\title{
Olmsted syndrome
}

\author{
Abdalla M. Attia, Ola A. Bakry \\ Department of Dermatology, Andrology and S.T.Ds, Faculty of Medicine, Menoufiya University, Menoufiya, Egypt.
}

Corresponding author:

Ola Bakry

Department of Dermatology, Andrology and S.T.Ds

Menoufiya University Hospital

Shibeen El Koom

32817 Menoufiya Governorate

Egypt

E-mail:drola_2007@yahoo.com

Key words:

alopecia, feet, genodermatosis, Olmsted syndrome, palmoplantar keratoderma

\begin{abstract}
Background: Olmsted syndrome is a rare keratinization disorder characterized by a combination of periorificial keratotic plaques and bilateral palmoplantar transgredient keratoderma. Other clinical manifestations include diffuse alopecia, leukokeratosis of the oral mucosa, onychodystrophy, hyperkeratotic linear streaks, follicular hyperkeratosis and constriction of digits.
\end{abstract}

Main observations: We report a case of Olmsted syndrome in a 5-year-old male presented by mutilating palmoplantar keratoderma, perioral keratoses and linear hyperkeratotic lower limb plaques.

Conclusions: Olmsted syndrome is a rare genodermatosis with only 43 cases reported so far. We present another case of the disease. (J Dermatol Case Rep. 2013; 7(2): 42-45)

\section{Introduction}

Olmsted syndrome (OS) is a genetic disease that presents with symmetrical sharply defined mutilating hyperkeratotic plaques on the palms and soles, associated with periorificial keratotic plaques. ${ }^{1}$ Other clinical findings include flexion deformities of the fingers, localized alopecia, leukokeratosis of the tongue, short stature and laxity of the large joints. Additionally, constriction of digits, onychodystrophy, linear hyperkeratotic follicular streaks and acral hyperhidrosis had been reported. Rare findings include ichthyotic lesions, absent premolar teeth, hearing loss for high frequencies and sclerosing cholangitis. ${ }^{2}$

\section{Case Report}

A 5-year-old male presented with massive keratoderma affecting his hands, feet and perioral area. He was the first child of non consanguineous healthy parents. Lesions started to develop at 8 months old and progressed over few months duration with development of painful fissures. Family history was non contributary. On examination, the patient was generally well and his physical, mental and hearing developments were normal. There was no evidence of an associated systemic disease. Both hands and feet showed sharply marginated, fissured, massive hyperkeratotic plaques with subungual hyperkeratosis. Hyperkeatosis extended over the dorsal aspect of figers and both sides of ankles. All digits showed flexion deformity at the distal interphalangeal joints. Sharply marginated, thick, verrucous, and erythematous hyperkeratotic plaques were seen around the mouth. In addition, linear hyperkeratotic streaks were seen on the front and sides of both thighs (Fig. 1). The patient had normal developmental milestones but the hyperkeratotic plaques caused inability to walk and flexion deformity caused inability to grasp. Hair, teeth and mucosal examination revealed no abnormality. Routine laboratory tests and serum zinc were all normal. Skin scraping and $\mathrm{KOH}$ examination was negative for fungi. X-ray of both hands and feet showed terminal osteoprotic changes and flexion deformity of digits (Fig. 2). Skin biopsy was taken after taking mother's consent. Histopathological examination of hematoxylin and eosin-stained section revealed hyperkeratosis, acanthosis and mild perivascular chronic inflammatory dermal infiltrate (Fig. 3). Based on clinical, laboratory and radiological findings, the diagnosis of OS was reached. Topical urea $20 \%$ and salicylic acid $0.5 \%$ under occlusion were described with some improvement. 


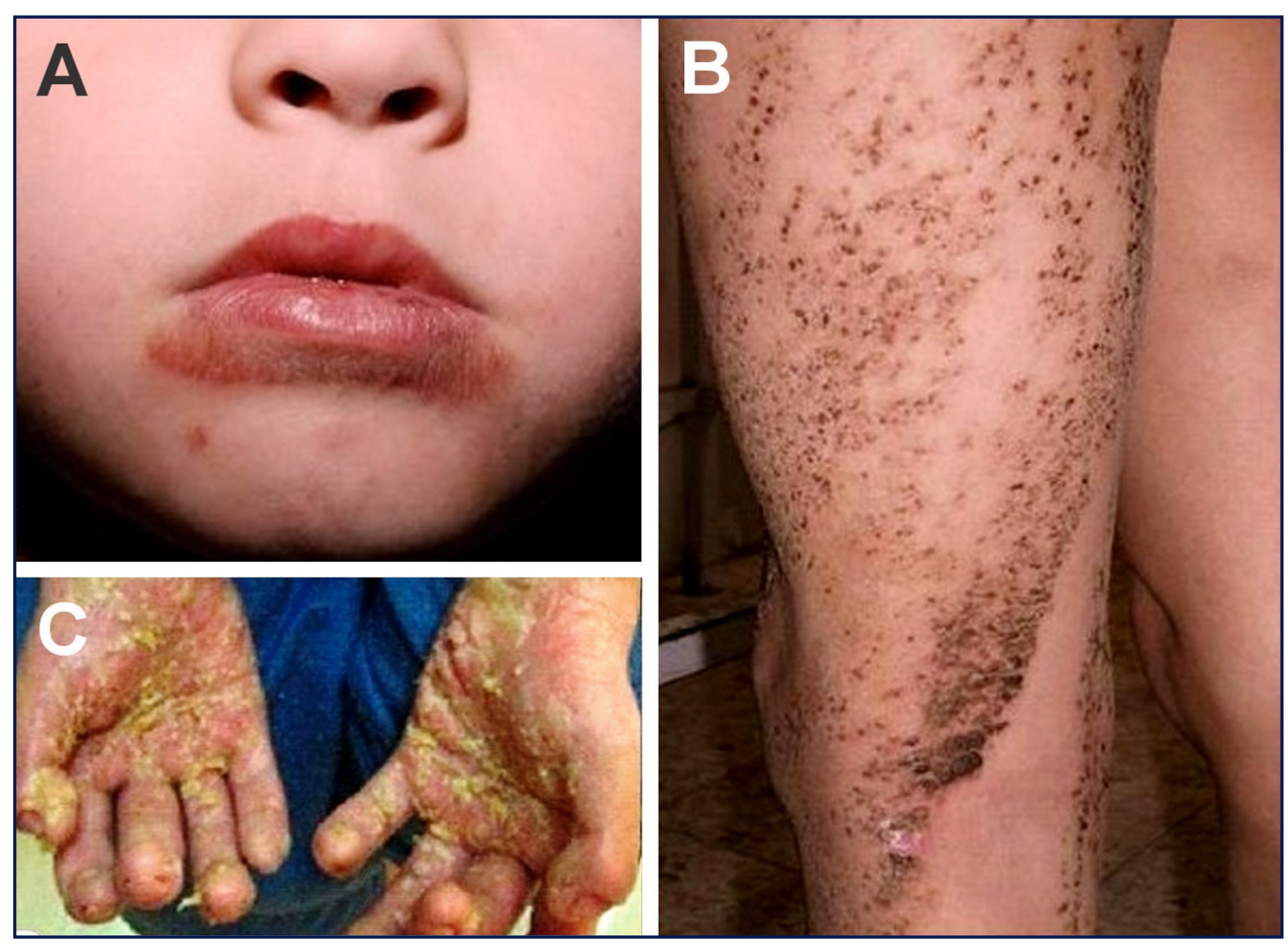

Figure 1

A) Perioral keratoderma; B) Linear keratotic lower limb plaques; C) Diffuse fissured palmoplantar keratoderma with flexion deformities of fingers.
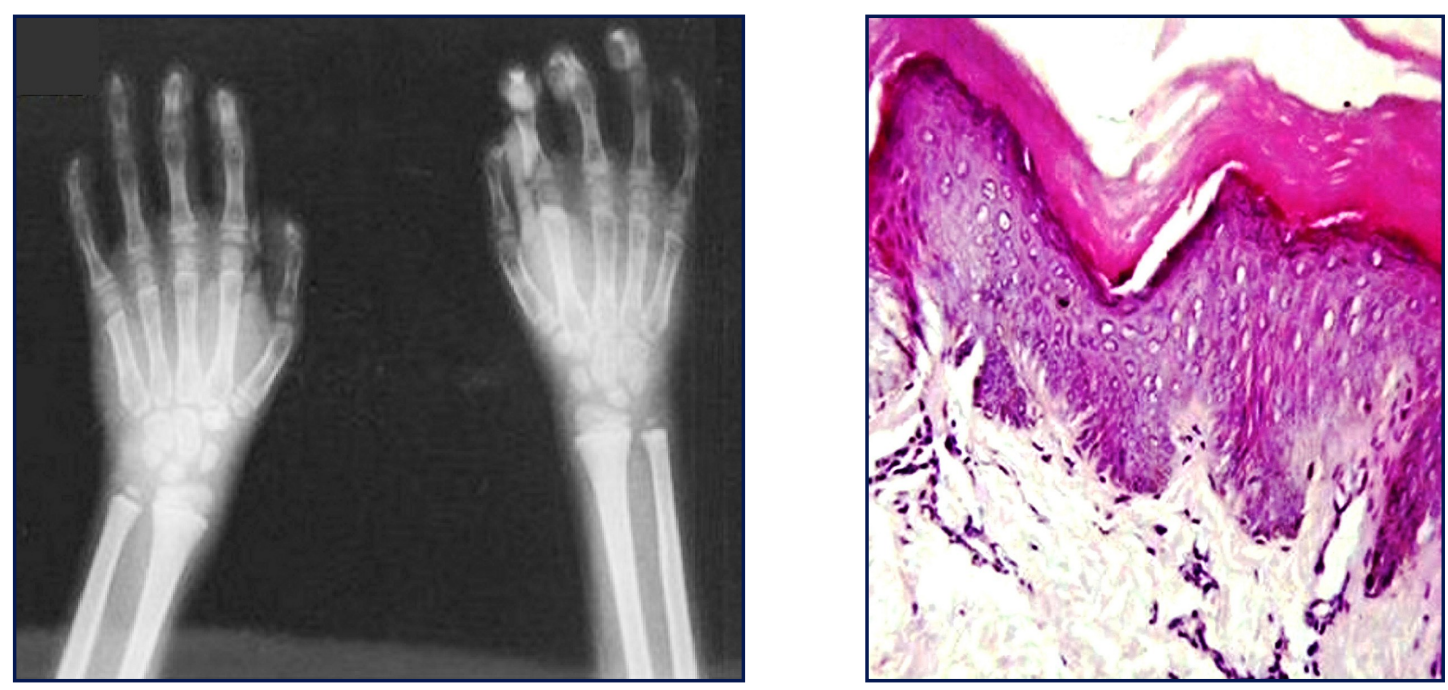

Figure 3

A photomicrograph showing orthokeratotic hyperkeratosis, acanthosis and chronic inflammatory dermal infiltrate (hematoxylin and eosin X100).

Figure 2

$X$-ray of both hands showing flexion at distal interphalangeal joints and abnormalities in distal phalanges.

\section{Discussion}

The first case of OS was reported in 1927 as a combination of congenital palmoplantar keratoderma with periorificial hyperkeratosis. ${ }^{1}$

These two main symptoms are the hallmarks for diagnosis of this condition. ${ }^{3}$ Although, the thickness of the skin lesions differ during the development of the disease, most lesions tend to become thicker and harder with time. ${ }^{4}$ Progression of the keratoderma may lead to deformities, constrictions

and eventually to spontaneous amputations. OS patients may have a higher susceptibility to develop epidermal tumors. ${ }^{5}$

This syndrome seems to be of sporadic occurrence ${ }^{6}$ although a familial case possibly due to autosomal dominant transmission $^{7}$ and another case with X-linked dominant inheritance in two monozygotic male twins had been reported. ${ }^{8}$ Kress et al. ${ }^{9}$ found a defect in the expression of mature epidermal keratins (types 1 and 10) and persistence of acidic keratins (types 5 and 14) in the involved epidermis. Several genes implicated in the pathogenesis of other keratodermas 
including KRT1, GJB2, SLURP1, and LOR were found normal, at least in one patient. ${ }^{8}$

OS has to be differentiated from other severe forms of PPK, such as Vohwinkel syndrome, Mal de Meleda Syndrome, Tyrosinemia type II, Pachyonychia congenita and Papillon-Lefèvre syndrome (Table 1). Acrodermatitis enteropathica also needs to be excluded by measurement of zinc levels. ${ }^{2}$

There is no satisfactory treatment for this condition. Topical treatments include solution of potassium permangenate, wet dressing, salicylic acid in various concentrations, boric acid, urea, tar, retinoic acid, shale oil, corticosteroids and prolonged soaking of the affected parts in warm water., ${ }^{4,5}$
Non of these is the best effecacious. Application of a hydrocolloid dressing can decrease pain in patients with deep fissures. $^{3}$

Oral retinoids have proved effective in some cases. ${ }^{10,11}$ Other systemic treatment with antihistamines, vitamins $E$ and $\mathrm{A}$, antimicrobials and corticosteroids have also been used anecdotally with no consistent benefits. ${ }^{12}$

For non-responsive patients, full-thickness excision of hyperkeratotic plaques followed by skin grafting is another therapeutic option to alleviate the pain. ${ }^{13}$ This treatment may improve flexion contracture of the fingers, but the risk of recurrence persists. ${ }^{10,11}$

Table 1. Comparison between OS and other Palmoplantar Keratoderma Syndromes.

\begin{tabular}{|c|c|c|c|c|c|c|}
\hline & Olmsted Synd & Vohwinkel Synd & $\begin{array}{l}\text { Tyrosinemia } \\
\text { type II }\end{array}$ & $\begin{array}{l}\text { Pachyonychia } \\
\text { Congenita }\end{array}$ & Mal De Meleda & $\begin{array}{c}\text { Papillon Le Fevre } \\
\text { Synd }\end{array}$ \\
\hline PPK & Diffuse & Honeycomb & $\begin{array}{l}\text { Painful } \\
\text { callosities }\end{array}$ & Variable & $\begin{array}{l}\text { Malodorous, } \\
\text { honeycomb }\end{array}$ & Diffuse \\
\hline Mentality & Normal & Normal & MR & Normal & Normal & Normal \\
\hline Hearing & Normal or lost & Lost & Normal & Normal & Normal & Normal \\
\hline Teeth & $\begin{array}{l}\text { Normal or lost } \\
\text { premolar teeth }\end{array}$ & Normal & Normal & $\begin{array}{c}\text { Normal, } \\
\text { neonatal teeth } \\
\text { may be present }\end{array}$ & Normal & $\begin{array}{l}\text { Periodontosis, } \\
\text { teeth loss }\end{array}$ \\
\hline Hyperhid & May be present & Absent & May be present & Normal & Normal & May be present \\
\hline $\begin{array}{l}\text { Linear } \\
\text { Hyperkerat }\end{array}$ & May be present & $\begin{array}{l}\text { Elbows and } \\
\text { knees }\end{array}$ & Absent & Absent & Absent & Absent \\
\hline Nails & $\begin{array}{l}\text { Subungual } \\
\text { hyperk }\end{array}$ & Normal & Normal & Pachyonychia & $\begin{array}{l}\text { Onychgryphosis, } \\
\text { koilonychia }\end{array}$ & Normal \\
\hline Hair & Normal or lost & Normal & Normal & Normal & Normal & $\begin{array}{l}\text { Normal or } \\
\text { sparse }\end{array}$ \\
\hline Digits & $\begin{array}{c}\text { Flexion } \\
\text { deformity, } \\
\text { Spontaneous } \\
\text { amputation }\end{array}$ & Pseudoainhum & Normal & Normal & $\begin{array}{l}\text { Pseudoainhum } \\
\text { may be present }\end{array}$ & Normal \\
\hline Other features & $\begin{array}{l}\text { Leukokeratosis } \\
\text { of the tongue, } \\
\text { short stature, } \\
\text { joint laxity, } \\
\text { ichthyosis }\end{array}$ & $\begin{array}{l}\text { Starfish shaped } \\
\text { keratoses, } \\
\text { myopathy, } \\
\text { paraplegia, } \\
\text { ichthyosis }\end{array}$ & $\begin{array}{c}\text { Photophopia } \\
\text { and corneal } \\
\text { ulcers }\end{array}$ & $\begin{array}{c}\text { Epidermal cysts, } \\
\text { Corneal } \\
\text { leukokeratosis }\end{array}$ & $\begin{array}{l}\text { Lingua plicata, } \\
\text { Syndactyly, } \\
\text { high-arched } \\
\text { palate, PP } \\
\text { Hypertrichosis }\end{array}$ & $\begin{array}{l}\text { Recurrent } \\
\text { cutaneous and } \\
\text { systemic } \\
\text { pyoderma, } \\
\text { psoriasiform } \\
\text { plaques }\end{array}$ \\
\hline
\end{tabular}

PPK: Palmoplantar keratoderma; Hyperhid: Hyperhidrosis; Hyperkeratot: Hyperkeratosis; Synd: Syndrome; MR: Mental retardation. 


\section{References}

1. Olmsted HC. Keratodermia palmaris et plantaris congenitalis: report of a case showing associated lesions of unusual location. Am J Dis Child. 1927; 33: 757-764.

2. Bergonse FN, Rabello SM, Barreto RL, Romiti R, Nico MM, Aoki V, Reis VM, Rivitti EA. Olmsted syndrome: the clinical spectrum of mutilating palmoplantar keratoderma. Pediatr Dermatol. 2003; 20: 323-326. PMID: 12869154.

3. Vosynioti V, Kosmadaki M, Tagka A, Katsarou A. A case of Olmsted syndrome. Eur J Dermatol. 2010; 20: 837-838. PMID: 20876042.

4. Mevorah B, Goldberg I, Sprecher E, Bergman R, Metzker A, Luria R, Gat A, Brenner S. Olmsted syndrome: mutilating palmoplantar keratoderma with periorificial keratotic plaques. J Am Acad Dermatol. 2005; 53: S266-272. PMID: 16227106 .

5. Ogawa F, Udono M, Murota H, Shimizu K, Takahashi H, Ishida-Yamamoto A, lizuka H, Katayama I. Olmsted syndrome with squamous cell carcinoma of extremities and adenocarcinoma of the lung: failure to detect loricrin gene mutation. Eur J Dermatol. 2003; 13: 524-528. PMID: 14721769.

6. Al-Mutairi N, Sharma AK, Nour-Eldin O, Al-Adawy E. Olmsted syndrome: report of a new case with unusual features. Clin Exp Dermatol. 2005; 30: 640-642. PMID: 16197376.
7. Tang L, Zhang L, Ding H, Wang X, Wang H. Olmsted syndrome: a new case complicated with easily broken hair and treated with oral retinoid. J Dermatol. 2012; 39: 816-817. PMID: 22414321.

8. Cambiaghi S, Tadini G, Barbareschi M, Caputo R. Olmsted syndrome in twins. Arch Dermatol. 1995; 131: 738-739. PMID: 7778937.

9. Kress DW, Seraly MP, Falo L, Kim B, Jegasothy BV, Cohen B. Olmsted syndrome. Case report and identification of a keratin abnormality. Arch Dermatol. 1996; 132: 797-800. PMID: 8678572.

10. Larrègue $M$, Callot V, Kanitakis J, Suau AM, Foret M. Olmsted syndrome: report of two new cases and literature review. J Dermatol. 2000; 27: 557-568. PMID: 11052230.

11. Santos OL, Amorim JH, Voloch K, Gomes M, Ramos-e-Silva M, Pereira Júnior AC. The Olmsted syndrome. Int J Dermatol. 1997; 36: 359-360. PMID: 9199984.

12. Lucker GP, Steijlen PM. The Olmsted syndrome: mutilating palmoplantar and periorificial kertoderma. J Am Acad Dermatol. 1994; 31: 508-509. PMID: 8077485.

13. Bédard MS, Powell J, Laberge L, Allard-Dansereau C, Bortoluzzi P, Marcoux D. Palmoplantar keratoderma and skin grafting: postsurgical long-term follow-up of two cases with Olmsted syndrome. Pediatr Dermatol. 2008; 25: 223-229. PMID: 18429785. 